\title{
La pluma férrea: escribir la vida. El Kaddish por el hijo no nacido de Imre Kertész
}

\begin{abstract}
Andreas Ilg
“ ‘No!', dije enseguida, en el acto, sin titubear”, inicio del Kaddish por el hijo no nacido de Imre Kertész, comienzo de una escritura que liquida identidades y abre con pluma férrea una fosa en el aire como campo horadado de la memoria. Principio de una mnemografía en tres etapas en las que la no existencia del hijo liquida radical y necesariamente la del Yo narrador. La obra Yo, otro y Liquidación realizan esta transformación entintada, liquidada de una forma cautivante.

" 'No!', I said immediately, in fact, without hesitation", inception of Kaddish for the unborn child by Imre Kertész and starting point of a writing which dissolves identities and, with an iron feather, digs a grave in the air like a perforated field of memory. Opening of a mnemography in three stages in which the non-existence of the child liquids radically and necessarily the I of the narrator. The works $M e$, other and Liquidation realize this inked and liquid transformation in a captive way.
\end{abstract}



Andreas Ilg

Universidad Nacional Autónoma de México

La pluma férrea: escribir la vida.

El Kaddish por el hijo no nacido de Imre Kertész

Sólo por nuestras historias podemos saber que nuestras historias han llegado a su fin; de lo contrario viviríamos como si aún diéramos continuidad a algo (a nuestras historias, por ejemplo), es decir viviríamos en el error.

B al menos tenía una historia, aunque fuese una historia inenarrable e incomprensible.

Yo no llego ni a eso. Yo debo contar la historia de B para ver mi vida como una historia $[\ldots]$.

KESERU

Contar una historia como si fuese la de otro, quizás sobra decirlo, revela todo el poder ficcional de la literatura, un poder que habita toda práctica de escritura y, ante todo, la práctica literaria. Este "como si" incluso puede apoderarse de esta práctica misma, por ejemplo, escribiendo como si se aplicara pinceladas sobre un lienzo o como si se usara un cincel sobre un bloque de mármol — ¿acaso sobre una lápida sepulcral?_. 
Las analogías a la herramienta de la escritura, a esta pluma que vierte tinta sobre la hoja blanca, pueden ficcionalizar la experiencia gráfica a tal grado que llegan a plasmarse en una jeringa que aspira sangre y hasta incluso en un martillo que golpea los oídos. En el caso de Imre Kertész, esta herramienta - que conserva todo su vínculo con el hierro- ha tomado forma de una pala, una pala para cavar fosas, para cavarlas en los campos que, vale subrayarlo, no se restringen a los de Auschwitz, Buchenwald, Monowitz.

Imre Kertész, sobreviviente de los campos de concentración, es escritor de novelas que labran el terreno de la memoria, revolviendo y removiendo la tierra para sembrar una nueva experiencia en la fosa expuesta, proponiendo una nueva forma de leer la memoria. Es el autor de varias obras, de las que elegimos el Kaddish por el hijo no nacido, novela escrita en 1990 y traducida al español en $2001^{1}$ y novela inaugural de esta nueva forma de lectura. Se trata de una novela que, a través de la escritura, condensa, por un lado, una fuga musical que suena y obliga a seguir cavando, como aquella fuga tocada por una orquesta en los campos de concentración, por el otro, una oración judía a la vida para los que ya cesaron, para los hundidos, los salvados, para los que no habrán podido ni hundirse ni salvarse; final y primordialmente para un hijo, el hijo no nacido. Esta novela marca un cambio en la obra de Imre Kertész y constituye el inicio de una escritura "negativa" y con tinta negra que recorre sin cesar los recovecos de la memoria, refiriéndonos con "negativa" al comienzo de una autoliquidación que, una vez recorridos tales recovecos, los inunda. Sin embargo, no se trata de una excavación arqueológica ni de una sepultura de reminiscencias. En relación con dos

\footnotetext{
${ }^{1}$ De ahora en adelante, las referencias a esta obra se harán entre paréntesis con una "K" que se encuentra en el texto. La traducción aquí citada se publicó en Madrid por El Acantilado, 2002 [1990]. Citas a otras obras indicarán la primera letra del título respectivamente.
} 
otras novelas encabezadas por el Kaddish por el hijo no nacido, Imre Kertész cuenta la historia de otro que narra una historia de alguien más, simulacro que manifiesta una doble enajenación literaria que permite el juego de la alteridad, de una otredad que liquida radicalmente la identidad. Las dos novelas que retoman el hilo del Kaddish, son Yo, otro (2002 [1997]) $)^{2}$ y Liquidación (2004 [2003]), ${ }^{3}$ obras que retuercen la trama del Kaddish en una trenza de enajenación finiquitante: yo, otro y, al fin y al cabo, yo-otro liquidado, causa por la que también las hemos consultado. Debido a esta autoliquidación, no empezamos a hablar de Imre Kertész como autor húngaro o escritor judío, sino de Imre Kertész, narrador. Pero también, y no hay que olvidarlo, Imre Kertész sobrevive a los campos de concentración. Estas tres huellas: ser judío, ser húngaro y sobrevivir a Auschwitz, atraviesan su obra como un hilo que sutura y que deja una marca en el corpus textual, una cicatriz literaria.

Es a Auschwitz, significante recurrente en Kertész y en el que convergen una serie de cadenas como en un núcleo - quizás un núcleo gordiano-, al que se intenta recortar, circunscribir y, en la trilogía kertésziana, ${ }^{4}$ cavando una fosa en el aire con una pluma de fierro. Su condición judía y, hasta junto con ella, también su nacionalidad húngara, surgen de este núcleo y se deshilvanan hacia la superficie. Desde las profundidades brotan, junto con aquel retoño del germen, que fue sumergido

2 A esta obra se hará referencia mediante la letra "Y": Madrid, El Acantilado, 2002 [1997].

${ }^{3}$ Haremos referencia a esta novela con la letra "L" en los paréntesis. Se trata de I. Kertész, Liquidación, México, Alfaguara, 2004 [2003].

${ }^{4} \mathrm{Si}$ podemos hablar de una trilogía, pienso en que justamente comienza con Kaddish..., y se prolonga en Yo, otro y Liquidación. Es más, Liquidación resignifica Yo, otro y, esta novela a su vez, y junto con Liquidación, ambos, reconstituyen el Kaddish.

Minh Tran Huy, en su artículo sobre Imre Kertész, "De l'enfer au néant", afirma que: "Être sans destin amorce une trilogie prolongée par Le Refus et le magnifique Kaddish pour l'enfant qui ne naîtra pas [...]" [Être sans destin inicia una trilogía prolongada por Le Refus y el magnífico Kaddish pour l'enfant qui ne naîtra pas] 
en la tierra surcada del papel blanco de la escritura. Si renace, si resucita en esta nueva escritura, no deja de llevar la inscripción fatal en el antebrazo, incluso en el muslo de aquel niño que sobrevivió y del que habla desde siempre: es este niño que era él cuando fue deportado a Auschwitz y cuya historia narra en Sin destino (1975 [2001]). Es el niño que no nació en la novela Kaddish por el hijo no nacido, es el otro en el que se convirtió el narrador en Yo, otro, y es "B" de Liquidación. La supervivencia en otro es lo que niega el ser judío y lo que constituye la única senda viable: el hijo. La condición judía vuelve fantasmáticamente en la condición de extraño (no de cualquier extraño): "el verdadero nombre de mi calidad de 'extraño' es el de judío" escribe todavía en Yo, otro y lo piensa junto con la cuestión de ser llamado "escritor húngaro". Sigue: "Para que un judío sea aceptado como húngaro en la actualidad (y esta actualidad ya dura más de siete décadas) debe cumplir ciertos requisitos que, para ser breve, conducen básicamente a la autoliquidación". (Y, 97; la cursiva es mía). Esta autoliquidación es dejar de ser el escritor que es. ¿Acaso no es un elegante giro — sin quitarle el que sea urgente- conducir esa autoliquidación a través de la tinta de otro? Otro que es húngaro y que es judío, otro que lleva la marca numérica en el muslo, otro que reza, que existe gracias a que escribe, a que escribe él y aquel otro. En el Diario de la galera escribe: "Ser 'húngaro' no es menos absurdo que ser 'judío’; y ser ‘judío’ no es más absurdo que existir" (D,222)..$^{5}$ El énfasis es en esta última afirmación: "ser 'judío' no es más absurdo que existir”. El Kaddish es una oración judía, pero para Kertész es claro: “ "Es una oración de un judío no creyente " . ${ }^{6} \mathrm{El}$ “ ¡No!” que gritaría

(Minh Tran Huy, "De l'enfer au néant", en Le magazine littéraire, 438, enero de 2005, 53).

${ }^{5}$ La referencia con la letra "D" es a I. Kertész, Diario de la galera, Madrid: El Acantilado, 2004 [1992].

${ }^{6}$ Entrevista "Existen medios para dominar al hombre" entre I. Kertész y H. Terstch, El País, 11 de marzo de 2001. 
el hijo, si hubiese nacido, es ese " ¡No quiero ser judío!"” (K, 109). Y volviendo al Diario de la galera, leemos ahora: "Cuando digo, pues, que soy judío, digo que soy negación [...]" (D, 50). La condición judía es tan fundamental en toda la obra de Kertész, desde 1975 hasta nuestros días, que se imbrica con la "libertad de autodeterminación". ¿Y no es que esta libertad se logra precisamente por la inmersión y el renacimiento en otro, en la existencia de otro, de este otro que, a partir del Kaddish, es el hijo? De la "libertad de autodeterminación" habla en una conferencia de Hanover en el año 2002: Se trata de "poder ser aquel que uno es". ${ }^{7}$ Más adelante afirma:

A Edmond Jabès, un escritor francés, se remite la expresión de que la dificultad de ser judío es igual a la dificultad de escribir. Hasta ahora nadie ha podido formular tan claramente mi propia situación. Y, no obstante, percibo una diferencia importante. Que soy escritor, éste es el resultado de mi libre autodeterminación. Al contrario, judío nací. Sin embargo, para unir en una única cualidad mi ser escritor y mi judeidad, debía percibir mi judeidad de la misma manera como percibo la más depurada realización de una obra de arte: es decir, como tarea. ${ }^{8}$

Unir la escritura y el ser judío se han convertido en una tarea, la tarea de excavar, no para descubrir una historia enterrada sino para desarraigar y dejar en el hueco de la tierra una semilla, esta semilla engendrada y generadora de la escritura. Imre Kertész liquida el ser escritor, judío y húngaro, y queda por preguntar si incluso, al final, Kertész no habrá liquidado el mismo ser escritor. No obstante, esta semilla que brota en la fosa vacía es la que sale a la luz con su primer retoño, con el

${ }^{7}$ Conferencia del 10 de octubre de 2001, traducido por Kristin Schwamm del húngaro al alemán. Publicado en: Frankfurter Allgemeine Zeitung, Feuilleton, 14 de marzo de 2002. La traducción del alemán al español es mía.

${ }^{8}$ Ibidem. 
vástago a través de las novelas Kaddish por el hijo no nacido, Yo, otro y Liquidación.

Visitar estas tres obras de Kertész es entrar en un laberinto de recorridos entintados por una historia que no pertenece más al autor, en las que el autor se ha convertido en narrador, y éste a su vez en narrador de una historia de otro. Un laberinto que cuenta la otredad y que liquida toda autorreferencia sobre la marcha de la escritura. Esta entrada al laberinto literario de Imre Kertész impide que se lo recorra con un solo y recto itinerario; no se llega a un lugar sino a perder. El camino se vuelve errante, angustiante, una inmersión en la tinta negra y espesa de esta autoliquidación. La escritura resultante de esta visita es el intento de calcar varias de las encrucijadas que han permitido reconocer el camino trazado, y "encontrarme", encontrarnos, encontrar a este otro que no deja de narrar una historia... la de Keseru, la de B, la de György Köves, la de Kertész, la nuestra. Este calcado en forma de ensayo no sólo es el negativo de la escritura sino también del campo en el cual se inscribió, en el cual se cavó, el lugar de esta fosa hiante y vacía.

Intentamos, estimado lector, penetrar este artificio kertésziano, advirtiendo desde el inicio que la entrada no puede ser nuestra salida. No sirve de nada comenzar con un hilo conductor, pretendiendo que nos guíe en el retorno. Sólo sirve empezar con la espera de que nos acostumbremos a la oscuridad para discernir algunas figuras como siluetas desdibujadas.

La entrada es brusca y arrastra subrepticiamente, como en un desliz...

“ ‘No!', dije enseguida, en el acto, sin titubear [...]” (K, 7); así inicia el Kaddish por el hijo no nacido. “¡No!” exclama el narrador, y ese No resonó en el comienzo y a lo largo de mi lectura de su obra, resonó como el eco de un grito fantasmal imperativo. Un “¡No!” violento y un eco que reflejaban los muros del laberinto literario, un «№!» que estremecía; ¿era 
este “¡No!” lo que, en un principio, me había causado repulsión con tanta violencia? ¿Era el hilván negativo que unía fragmentos en una tela de parches y donde no sabía yo cómo realizar la costura final, es decir, las puntadas de mi lectura? o ¿acaso era el incesante hilo que, una vez comenzado con ese “No!” al inicio de una cadena nudosa, recorría el laberinto sólo para sumergirme al final con el narrador en el centro de sus recovecos?

“Sumergirme, ¡Dios mío!” (K, 147). ¡Dios mío!, le ruega, como quien clama que lo salven. Cómo no leer en esta súplica el eco de un salmo:

¡Sálvame, oh Dios, porque las aguas

me llegan hasta el cuello!

Me hundo en el cieno del abismo, sin poder hacer pie;

he llegado hasta el fondo de las aguas, y las olas me anegan. ${ }^{9}$

Pero el narrador no clama ser salvado, ni se hunde; al contrario, pide sumergirse. Son las "aguas negras y crecidas de un río oscuro” (K, 147). ¿Habrán sido aguas como las de los ríos que desembocan en el Aqueronte y por los que Odiseo bajaba al Hades? ¿Y cerca de la desembocadura de ambos ríos habrá cavado esa fosa así como se le había pedido a Odiseo que cavara para los muertos, vertiendo miel y leche? ${ }^{10}$

“¡No!” Y de nuevo es ese “¡No!”, precisamente ese "¡No!” que, por paradójico que resultara, me atraía durante el recorrido por —o la incursión a— este terreno de páginas numerosas sobre las que se había vertido ese negruzco líquido en largas hileras monofrásicas. Con tanta vehemencia se repetía ese “No!”, siempre en los puntos de unión, que parecía que se

${ }^{9}$ Salmo 69, en Biblia de Jerusalén, Bilbao, 1975, 755.

${ }^{10}$ Véase Homero, Odisea, canto X, versos 511-519. 
zurcieran pedazos recortados en un patchwork de párrafos como si las costuras fueran callejones y cerradas de un laberinto "textil-textual".

Este laberinto construido de una escritura de recuerdos, desencadenada a partir de un encuentro en una caminata por el hayal cerca de su casa de refugio, no ofrece otra salida que la misma entrada, una fosa, pero no una tumba en el suelo, ni junto a los ríos por los que había bajado Odiseo, no, una "fosa en el aire"; 11 esa entrada y salida que es la única escapatoria anímica o, para excursionar en tierras antaño abandonadas, un verdadero psicoducto, ${ }^{12}$ una salida del alma hacia el cielo abierto, un éxodo. Pero si la fuga gaseosa cava una fosa en los aires, con una pluma cual pala, y penetra la tinta en la blancura de las páginas, hundiendo al lector en el remolino de "las aguas negras y crecidas de un río oscuro", ¿qué más queda que esta "negra leche del alba"13 que bebemos y bebemos sin cesar? ¿Acaso la escritura?

“ ‘No!', gritó, chilló algo en mí enseguida, en el acto [...].” $(\mathrm{K}, 10)$. Así es cómo el narrador logra cautivar al lector; me logró capturar, desde el inicio, como el doctor Obláth en la novela aquel día en aquel bosque de hayas. ${ }^{14} \mathrm{Y}$ de ahí en adelante,

${ }^{11}$ Referencia de Kértesz a un poema de Paul Celan que no sólo constituye un fragmento del epígrafe al Kaddish sino que se manifiesta en el trazo mismo de la pluma de Kertész.

${ }^{12}$ El psicoducto es el nombre del canal que presenta la pirámide de Kéops en Gizeh y que, según lecturas arqueológicas, servía para conducir el alma desde la recámara que acogía el sarcófago hacia fuera. La referencia a "las tierras antaño abandonadas" remite al Exodus, que además hace juego con el camino hacia fuera, que en este caso no es otro que la vía que una vez sirvió de entrada.

${ }^{13}$ Véase Paul Celan "Fuga de la muerte", en Obras completas, pp. 423, 424.

${ }^{14}$ Es un dato curioso que se trata de un bosque de hayas, pues "hayas" en alemán son "Buchen", y "bosque de hayas" significa, por lo tanto, "Buchenwald". El traductor inglés de la novela Kaddish, Tim Wilkinson, subraya que en la versión americana se tradujo "oak forest or glade" pero que se trata precisamente de "beech wood: 'Buchenwald' [And the tree motif is picked up later, with an oblique reference to a line from one of Horace's Odes, quoted by Schopenhauer and Nietzsche: 'Why do you torture your poor reason for insight into the riddle of eternity? Why do we simply not lie down under the high plantane? or here under 
sigue con una ráfaga de ideas que arrastran al lector en párrafos eternos, con puntos esparcidos, comas diseminadas aquí acullá, como si fueran astillas flotantes, reminiscencias de un náufrago advenidero, un mirar adelante mirando atrás. En el mar de aguas negras, entintadas en esas letras de las que dice que "arrastran", y que recubren su vacío de locuacidad, volteo la mirada hacia atrás, al mero comienzo, y leo: "Kaddish por el hijo no nacido"; me corrijo, pues antes había creído que se tratase del "Kaddish por un hijo no nacido". ${ }^{15}$ Pero es justamente que entre "un hijo" y "el hijo" se abre el abismo, una hendidura profunda entre "mi existencia vista como posibilidad de tu ser" y "tu no existencia como liquidación radical y necesaria de mi existencia. Porque sólo así adquiere sentido [...] vivir y escribir, lo uno o lo otro, ambas cosas a la vez, porque el bolígrafo es mi pala, cuando miro adelante miro única y exclusivamente atrás [...]" (K, 42; el énfasis es mío.) "Mi existencia — tu no existencia_, se manifiestan en esta conjugación de la vida y de la escritura que es, al fin y al cabo, el trabajo que lo salva, "aunque sólo lo hiciera para la destrucción" (K, 145). La salvación que hace un par de instantes y con alusión a un salmo escuchamos en la aclamación al final del Kaddish por el hijo no nacido, es esta inmersión para la cual cava la fosa.

Se trata de la destrucción o la "liquidación radical y necesaria”.

this pine tree?"] (T. Wilkinson, "Kaddish for a Stillborn Child?", en The Hungarian Quarterly, vol. XLIII [168], invierno de 2002). El bosque de hayas es un bosque "tendente a ralo que resollaba de forma casi perceptible debido a una enfermedad que era acaso la tuberculosis: confieso mi ignorancia y falibilidad en cuestión de árboles, pues sólo reconozco al punto los abetos [pine tree] por sus hojas aciculares y también los plátanos [plantane] porque me gustan [...]" $(\mathrm{K}, 7)$.

${ }^{15}$ De hecho, los traductores del las versiones en inglés y en alemán, optaron por "un hijo": Kaddish for a child not born de C. C. Wilson y K. M. Wilson; Kaddish for an unborn child de T. Wilkinson; Kaddisch für ein nicht geborenes Kind, en la traducción alemana. Por el contrario, al francés se tradujo: Kaddish pour l'enfant qui ne naîtra pas. 
Son aquellas cavaduras de esta fosa en el aire, de esta vehemente negación que llega al apogeo en su Diario de la galera cuando dice: "soy la negación [...]"(D, 50). ¿Pero a qué se dirige ese "¡No!" con el cual comienza cada párrafo como si fuese una palada más de una larga excavación? ¿No es la excavación misma un acto positivo, como lo es la escritura, con bolígrafo cual pala o pluma férrea? ¿Y no es en el acto positivo de escribir y vivir que la negación como "autoliquidación" adquiere sentido? ¿Y qué es este enigmático mirar adelante mirando atrás como si se tratara de dos caras de la cabeza del Jano bifronte? Cuando grita, chilla “¡No!”, ¿qué es lo que se opone inmediatamente, en el instante, en el acto, sin que haya posibilidad ni siquiera de decidir? El narrador dice:

este "no" no era pues una decisión en el sentido de tomar una decisión libre entre un "sî" y un "no", no, este "no" era un reconocimiento, no una decisión que yo tomaba o podía tomar, sino una decisión respecto a mí, que de hecho no era una decisión, sino un reconocimiento de mi condena $[\ldots](\mathrm{K}, 41)$.

¿De qué condena se trata? ¿Una condena a liquidarse, a sumergirse como se sumerge la pluma en la tinta para escribir? La liquidación radical de la que habla con respecto a la noexistencia del hijo es una liquidación de sí mismo. ¿Acaso no se muestra en aquel vocablo este retruécano entre la eliminación mortal y el flujo escritural capaz de entintar la muerte o, acaso, la vida? Y en esto aparecen nuevamente "vivir y escribir, lo uno o lo otro, ambas cosas a la vez". Podemos escuchar mejor esta confluencia líquida de vida y escritura $-\mathrm{o}$ incluso de "escritura y muerte"- (cual si fuere tinta para escribir), si nos referimos a J. Semprún, quien "tenía que elegir entre la escritura y la vida" y advirtió que optó por la vida. ${ }^{16}$ La escritura

${ }^{16}$ Discurso con motivo del Premio de la Paz (1994). Contraportada del libro La escritura o la vida, Barcelona, Tusquets, 2002 [1995]. 
o la vida es "esta tarea de retorno a la vida, de luto de la escritura" ${ }^{17}$ fabricando "vida con tanta muerte [...] asumiendo esta muerte mediante la escritura"; y sigue Semprún: "pero la escritura me prohíbe literalmente vivir". ${ }^{18}$ En Kertész parece ser al contrario: aun cuando la escritura lo sumerge y lo liquida, el acto de escribir sirve "para soportar mi existencia; es más para justificarla" (D, 168). Y de nuevo se abre el campo semántico cual si fuese un abismo: el soporte de mi existencia. No es para soportarla, como suele decirse cuando se desea sobrellevar una pesadumbre sin saber cómo contrariarla; no, se trata de un soporte, como aquel que constituye la hoja para la escritura. El acto de escribir es el soporte de su existencia, es decir, de una existencia de escritura, de una existencia de un personaje, de aquel personaje que narra incesantemente - hasta sumergirse-, que narra el dolor de la existencia. Allí donde se hunde una existencia, la otra se sostiene gracias al soporte de la escritura. Y ahí está la diferencia entre hundirse y sumergirse, pues el último es un acto deliberado. Es el descenso al inframundo que sólo les es permitido a los muertos, excepto si un ser vivo haya hecho una ofrenda y se atreve a bajar al reino de la ultratumba. ¿La escritura puede ser esta ofrenda? ¿O es ella misma el descenso o, en palabras de Kertész, el acto de sumergirse? ¿Logra entintar la muerte, fijarla en sus aguas negras? Lo que logra la escritura, escribe Kertész, es esto: la escritura resulta ser "un esfuerzo más bien vidente" en contraste con la vida, que es "un esfuerzo más bien ciego" La escritura, sigue Kertész,

se distingue por tanto de la vida, claro, y que tal vez se esfuerza por ver aquello por lo que se esfuerza la vida y, como no puede hacer otra cosa, repite la vida de la vida, copia la vida como si ella, la escritura, fuese vida, y no lo es de una manera fundamental $[\ldots](\mathrm{K}, 58)$.

${ }^{17}$ J. Semprún, La escritura o la vida, p. 212.

${ }^{18}$ Ibidem, 180. 
Sí, definitivamente no lo es. Pero hay algo en la escritura, que permite pasar de la copia a la creación. Si no es que cree vida, puede "fabricarla" 19 como se fabrica una serie de párrafos que inician, cada uno con una "negación", con este tan vehemente y estruendoso " ¡No!” Y en esta fabricación de escritura, repitiendo la vida de la vida, hay el "reconocimiento de mi condena", la condena de pasar con la escritura no a través de la vida sino a través de la muerte. Y por esta razón también es el bolígrafo con el que cava, cual si fuera una pala.

El "como si" es todo el poder de la escritura: muero como si hubiese muerto, y revivo cual si hubiera resucitado. La mirada adelante mirando atrás es esa repetición, una suerte de anamnesis, un recordar el futuro repitiendo el pasado. La vida, entonces se recuerda ad futurum, como si se realizara un relato a la inversa. No relata lo sucedido sino narra el porvenir. ¿Se trata de un truco peligroso de la escritura? Si en Yo, otro se pregunta "¿Por qué emborrono este papel con el bolígrafo?" $(Y, 82)$, contesta de la siguiente manera, en una enunciación sorprendente:

¿Qué es mi vida sino un relato? [Un relato en el cual caí "prisionero de una trampa sin salida..." y en el que...] narraría la lucha sin fin que se inició en mí de forma imperceptible, como los cambios que se producen en un germen, para que ascendiera de las profundidades insondables de la existencia a la superficie de la conciencia, y para que luego aceptara la existencia (mi existencia) con esta nueva conciencia.

Esto supone, como sigue, "una peregrinación eterna [...] hacia las cumbres que siempre azulean en lontananza; [...] mi

${ }^{19}$ Y aquí no hacemos alusión al significado moderno de la palabra "fabricar" sino refiriéndola a su origen latino: "faber" que es el "artista" o "artesano", aquel cuya obra es, en todo caso, una "maniobra" así como, en el caso del escritor, un "manuscrito". De hecho, es éste el sentido que encontramos en J. Semprún que surge a través del vocablo francés "fabriquer". 
vida es una dura lucha por la muerte [...]" (Y, 109, 110). Esta muerte buscada es el encuentro con una "fabricación" de vida —en palabras de Semprún_, una vida escrita de "tantas muertes”. ¿Puede lograr esto la escritura? ¿Escribir vida de tanta muerte? ¿Entintar la muerte? ¿Falta morir para ello? ¿Pasar esta muerte "azul" — como decía Victor Hugo—20 en "lontananza”? ¿No es un horizonte, el sempiterno horizonte azul de la muerte que constituye el descenso a la ultratumba - "Yo ya piso el vacío, si es que no voy descendiendo" (Y, 91)—, el entre dos mundos, el de los vivos y el de los muertos? "Me encuentro ahora - escribe - entre el umbral de la vida y la muerte, con el cuerpo vuelto hacia delante, hacia la muerte, $y$ la cabeza vuelta hacia atrás, hacia la vida, levantando el pie, indeciso." Lo escribe en el último párrafo de su novela $Y o$, otro, que finiquita con una respuesta a una interrogante: “ ¿Hacia dónde se dirige? Da igual, pues quien dé el paso ya no seré yo, sino otro..." (Y, 143). Tres puntos suspensivos dejan todo en el aire, inconcluso y anuncian el devenir escritural del epígrafe: " 'Yo: una ficción de la que a lo sumo somos coautores" ". La escritura lo salva: pasando al otro lado de ese abismo entre vida y muerte. Los tres puntos suspensivos son el sostén de ese "vacío" que aún está pisando. "Indeciso", dice. El descenso es para volver, por lo menos si se desciende o si se sumerge vivo. Esta inmersión viva para volver y narrar la propia historia, una memoria del porvenir, es una práctica de la muerte. Pero ante tal práctica, en el Diario de la galera lanza la pregunta por el cómo realizarla y contesta: "En primer lugar, escribiendo siempre desde la muerte (desde el otro lado del abismo)" (D, 252); salvando un abismo y hablar desde el otro lado. Es por medio de la escritura que se salva este abismo, mediante la escritura que se atraviesa tanta muerte para hacer vida, pero esta vida, para Imre Kertész, ya no será la suya sino

20 "La mort est bleue" [“Cadaver"], en Les Contemplations, agosto de 1855. 
la de otro. Sea que él lo escriba en un libro, en una serie de libros o el narrador en un papelito con este bolígrafo que "derramaba una sustancia que penetraba todo el tejido de lo proyectado, todas sus células [...]" (K, 103, 104), sea como fuere, vierte y advierte el líquido que penetra toda célula de esta "autoliquidación consciente" la que reaparece en tantas ocasiones a lo largo de su obra. La "autoliquidación" es escritural, gráfica; un grabado, una excavación, una obra inscrita e incluso cincelada con una pluma férrea. Pero también es la necesidad de la muerte para vivir. Sí, el hombre requiere la muerte para poder vivir. Sin muerte, la vida no es posible. La liquidación de su existencia por la no existencia del hijo es la imposibilidad de "sobrevivir" o de "pervivir" en la herencia vital, biológica de la cría de carne y hueso, del vástago del que hablamos en referencia a la semilla al principio; a saber, "la supervivencia de uno mismo que se prolonga y multiplica en los descendientes [...]" (K, 16).

El título Kaddish por el hijo no nacido logra estremecer cuando volvemos a leer con énfasis su pequeña preposición. Ahora el Kaddish no se dirige al hijo que nunca nació sino, justamente por "tu no existencia como liquidación radical y necesaria de mi existencia", se ora para el narrador. Por o "a causa de" este hijo no nacido que liquida "mi existencia", se reza el Kaddish. ${ }^{21}$ Es el hijo, el descendiente, que narra la muerte del padre. Además, el epígrafe —que originalmente se refería a una inscripción en la lápida sepulcral, a saber, el epi-

${ }^{21}$ Queda por verificar si el título original Kaddis a meg nem született gyermekërt permita esta interpretación. "még nem" en húngaro quiere decir "aún no" o "todavía no"; junto con un adjetivo, como es el caso de "született" se reduce a "no nacido" y no enfatiza en la partícula: "aún" o "todavía". De hecho, en la obra de Kertész es claro que este hijo no nació y no habrá nacido. La inquietud acerca del título original en húngaro se inscribe en una problemática más grande. Lamento no saber leer húngaro, lo que probablemente hubiese posibilitado pasar de una interpretación a rastrear los trazos deconstructivos del texto. Sin embargo, deseo extender mi agradecimiento a la traductora Judith Xantus (de Sin destino) y al traductor Adan Kovacsics, sin cuya traducción extraordinaria no me habría sido posible conocer la obra de Imre Kertész. 
tafio_-, de donde extraemos el fragmento: "luego subiréis como humo en el aire", es esta remembranza gráfica que no sólo atraviesa toda la obra de Imre Kertész sino anuncia el Kaddish y aquel personaje a cuya muerte se dirige. El bolígrafo cual pala es, en verdad, un cincel que graba este epígrafe en la superficie marmórea de la lápida inexistente ${ }^{22}$ que es el cuerpo del texto de la no existencia. Y el bolígrafo, cual pala, cava en lo real, deja un hueco, crea un surco que acoge la siembra, al igual que una tumba para acoger al muerto. Es la siembra de la semilla que germina y ascenderá de las profundidades insondables. La pluma es esta herramienta - de hierro por cierto- con la que crea una nueva existencia. Si el Kaddish es una oración a la vida que se reza durante el luto, toda esta obra de Imre Kertész resulta ser un Kaddish rezado al narrador, a través del narrador ${ }^{23}$ por ese otro que no nació pero que, en lugar del muerto, nacerá, que nacerá sólo y únicamente para rezar la inmersión del muerto. Todo el Kaddish ora por el narrador en su camino descendiente, a través de las aguas negras y crecidas. Siete años más tarde habrá escrito:

creí encontrar el magma candente e inspirador de la obra de teatro que estoy escribiendo: el lamento por la muerte del protagonista suicida se refiere a la desaparición de mi propia existencia creativa, de ese ser que en el transcurso de treinta años de trabajo secreto, productivo y, en el fondo, inofensivo, hizo salir del capullo el gusano de seda y creó aquel otro que ahora soy yo. [...] En la obra me condeno a mí mismo a muerte (lo hago en todos mis textos, no paro de morir) y, si sobrevivo a

${ }^{22}$ Que no sólo extrae su evidencia de que una fosa aérea no tiene lápida, sino que - al contrario de ser una evidencia lapidaria - constituye la "grave" insignia de la no existencia que atraviesa la obra y —anticipamos - la marca cual si fuese una grieta.

${ }^{23}$ Y que termina precisamente con el "Amén" (147) que declamarán el narrador del narrador muerto y nosotros, los lectores del relato y participantes de la oración del Kaddish: "Veymru: Amén!" 
la sentencia, seguiré huyendo en pos de nuevas muertes) [...] $(\mathrm{Y}, 65,66)$.

Esta huida en pos de nuevas muertes es "la fuga de la muerte", que en el Kaddish por el hijo no nacido ya es una referencia a Paul Celan, aunque siendo una referencia póstuma a la escritura, una alusión tan obvia que sólo hace falta recordarlo. ${ }^{24}$ No obstante, a la par, es una fuga musical, fuga aérea cual humo quemado y, last but not least, una "Fuge", una "Todesfuge": vocablo alemán ambiguo, pues remite a una juntura, una unión, así como, al contrario, a una ranura, una muesca, una hendidura. ${ }^{25}$ Se trata de una grieta sobre la lápida, una grieta en el torso de la obra, torso mutilado por una pluma dura. ¿Será una aguja con un hilo que atraviesa la blanda tela? ¿Qué más da? Corre la tinta, liquida con cada palabra del enunciador, incesantemente... Si atraviesa la aguja y punza el texto, lo hace con el grabado de ese “¡No!” Y sólo ese “¡No!” irrumpe de vez en cuando — ad oculos — en ese "hablar sin parar, en una suerte de ataque de verborrea, [...] mi locuacidad obsesiva" $(\mathrm{K}, 45)$. Pero en esta verborrea hay una constante zurcidura escritural. Ésta logra crear ese texto que no es la vida pero que la invoca, reinvoca y resucita. Imre Kertész, e incluso el narrador, que no deja de ser un truco problemático, pues "ya no soy yo, sino otro", se condensan en ese yo que es ya el narrador y ese otro que es otro narrado. El hijo no nacido que reza

${ }^{24}$ Como lo hace en el Diario de la galera, 210.

${ }^{25}$ El sustantivo alemán "Fuge" tiene una serie de acepciones que abren un enorme campo semántico: por un lado, "aus der Fuge sein" significa "estar fuera de quicio", temática que J. Derrida elaboró en Espectros de Marx, acudiendo, con respecto al vocablo alemán, a la obra de M. Heidegger sobre la sentencia de Anaximandro en Holzwege [Caminos del bosque o Senderos perdidos]. "Mit Fug und Recht" significa "con razón", "con perfecto derecho". Aparte hay las tres significaciones que ya mencionamos. El título del muy conocido poema de Paul Celan puede leerse en todos estos sentidos, es decir, como "fuga musical de muerte", "huida de muerte" (huida mortal o entendiendo que ni la muerte se queda) y "hendidura de la muerte" o "juntura de la muerte". 
por el ascenso de aquel muerto sumergido, lo resucita. Pero hay un velo sagrado que cubre toda esta textualidad cutánea, ¡Dios mío!, y puede palparse, sentirse, por debajo del que logran dibujarse las fisuras, grietas en la piel, hendiduras cicatrizadas por la misma escritura. Es un velo que no nos concierne tocar tan bruscamente.

Y no queda más que intentar hallar las marcas de la entintada autografía: En Yo, otro afirmó: "ya no sé si escribí o no el Kaddish por el hijo no nacido, esa novela de la que leo sin parar, por doquier, en alemán; y si la escribí, no sé cómo... pues he olvidado el escribir" (Y, 39). El haber olvidado el escribir es quizás una condición indispensable para escribirse o, como en aquella novela de la que ya no sabe si la escribió, para autoliquidarse. Pues es otro que ahora escribe, que esta vez lo escribe a él, desde el otro lado del abismo, a través de la muerte, en la que sumergió aquel que era antes. Pero no sólo queda un trazo mnémico borroso, sino incluso se interroga: “Realmente deseo escribir todavía?” (Y, 57). Lo que en Yo, otro se anuncia, cobra vida en la última novela Liquidación. Estremece el epígrafe. Es de Beckett, de nuevo: "Entonces entré en casa y escribí: / Es medianoche, / La lluvia azota los cristales. / No era medianoche. No llovía”. ¿Kertész habrá añadido: "ni era yo quien entró en casa y ni siquiera escribí"? En Liquidación se narra la historia de B (o de "Bé”); es el relato de otro que narra lo que pasó a $\mathrm{B}$, y de inmediato surge una reminiscencia: "yo era yo, B, el escritor y traductor del que había leído 'algo' sobre lo cual debía hablar a toda costa conmigo, dijo mi (entonces todavía futura, ahora ya ex) mujer, [...]" (K, 36). Lo leemos ya en la obra Kaddish por el hijo no nacido. "B" se suicida, y resuena en este suicidio todo el peso de la afirmación que leímos hace un par de instantes: "el lamento por la muerte del protagonista suicida se refiere a la desaparición de mi propia existencia creativa, de ese ser que [...] creó aquel otro que ahora soy yo" (Y, 65, 66). El lamento 
por la muerte del protagonista confluye con el rezo del Kaddish, converge con el otro que ahora es, ese otro de la escritura, de la nueva existencia escritural, ese otro ser escrito, escrito por otro, y producto textual, manufacturado, fabricado, ficcionalizado y, de facto, artificio literario.

Volviendo al epígrafe, encontramos ahora todo el poder de la ficción: la existencia del narrador liquidada por la no existencia del hijo, es la de ese yo-otro, de ese B, de este portador de "una B mayúscula y un número de cuatro cifras" $(\mathrm{L}, 33)$ que "nació [...] en uno de los barracones de Birkenau del campo de concentración que se conoce por el nombre de Auschwitz" (L, 39). La vuelta a Auschwitz es un retorno a la condición judía, en B del Kaddish en B de la Liquidación, en ese B cuya historia debe narrar.

En esta última novela, el protagonista busca un escrito que "B" debería haber dejado, un último escrito, antes de "sumergirse", junto con "las aguas negras y crecidas de un río oscuro", un río de tinta, un río de escritura. Se trata de un "Manuscrito, Mi escrito" (L,122), y "B" le pide a su ex mujer, que en Liquidación adquiere el nombre de Judit, que lo queme. Este escrito trata de "la lucha entre un hombre y una mujer. Al principio se aman. Luego, la mujer quiere un hijo del hombre, y él no se lo perdona" (L, 122). Voilà! Reaparece el nudo espectral y detonante del Kaddish por el hijo no nacido. Es esta obra misma la inmersión; no tiene que esperarse hasta el final, no tiene que pasar a rezar, sino toda ella es el Kaddish que declama aquel que sobrevive, que lo ve descendiendo y desapareciendo. $\mathrm{Y}$, sin embargo,...

“ ‘No!', enseguida, en el acto, sin titubear [...]” (K, 108). "-Porque no debía desearlo. — ¿Por qué no? -Por Auschwitz" (L,122,123)... Por Auschwitz. Es más que un abismo, es más que una inmersión, está escrito en la piel, inscrito, entintado, grabado, con aguja, con tinta negra de este río oscuro, de esa vena que atraviesa la obra pétrea, lápida aérea de una 
fosa en las nubes. Si en el Kaddish se interroga "¿si fueras una niña de ojos negros y de pequitas pálidas esparcidas alrededor de la nariz? ¿o un niño travieso de ojos de color azul grisáceo, alegres y duros como guijarros?” (K, 22, 39), aquellos hijos a los que su exmujer les pidió que lo saludasen, en su última obra, reliquia que se salva en Liquidación, por Liquidación y pese a Liquidación. Ambos reaparecen un breve instante: "Tengo dos hijos. Dos hijos medio judíos. Aún no saben nada. Duermen. ¿Quién les hablará de Auschwitz? ¿Quién de nosotros les dirá que son judíos? [...] ¿Y si no se lo dijéramos?" (L, 141).

De vuelta al epígrafe de nuestro ensayo: ¿Quién es Keseru? ¿Keseru y no, por ejemplo, Améry? ${ }^{26}$

Keseru es quien exclama: "No debo olvidar que quiero contar la historia de B (aunque sea para salvar así la mía)" (L, 57). La historia de B hundido en Kaddish por el hijo no nacido, de "yo" que dejó de ser yo para ya ser otro, ese Yo, otro que anuncia: "Sólo quiero seguir escribiendo mientras pueda, porque me gusta escribir" (Y, 60). Es el yo-otro renacido en la historia de B suicidado, contado por otro, por K., Kertész, que ya no es Köves, György Köves ${ }^{27}$ y que dejará de ser Kértesz, historia de esta "autoliquidación” en la tinta de B, de Keseru, contado por Keseru, protagonista de Liquidación, a cuyas espaldas, con "insistencia tozuda y torturante", centelleaba sus inútiles operaciones el ordenador fosforescente: "SIGUIENTE / CANCELAR" (L, 149).

"Sólo por nuestras historias podemos saber que nuestras historias han llegado a su fin"; y las historias de Imre Kertész que se manifiestan en ser escritor judío y húngaro, escritor de los campos de concentración, estas historias ya han llegado a su fin. Son las historias que ahora narra otro.

${ }^{26}$ Véase I. Kertész, Liquidación, 46.

${ }^{27}$ Véase I. Kertész, Sin destino, Barcelona: El Acantilado, 2003 [1975]. 
Quizás la trilogía kertésziana es una "Comedia en tres actos", debajo de la cual se lee: "La acción transcurre en Budapest, en 1990” (L,14). 1990: Kaddish por el hijo no nacido, oración por la vida de aquel narrador cuya existencia se liquida en la tinta negra sobre la hoja virgen, cual huellas en un paisaje nevado, contando la historia de alguien, suponemos de "B", "para ver mi vida como una historia". Si la escritura no sólo es un medio de expresión para Kertész, sino una forma de dar vida, atravesando la muerte, sumergiéndose en la "leche negra", no olvidemos: "el verdadero medio de expresión del hombre es la vida, decía él [B] siempre” (L, 123).

\section{REFERENCIAS}

Celan, Paul, 1999. "Fuga de la muerte", en Obras completas, Valladolid, Trotta.

Kertész, Imre, 2002. Conferencia, traducida por Kristin Schwamm del húngaro al alemán, en Frankfurter Allgemeine Zeitung, Feuilleton, 14 de marzo.

—, 2002. Kaddish por el hijo no nacido, Madrid, El Acantilado, [1990].

—, 2002. Yo, otro, Madrid, El Acantilado, [1997].

—, 2003. Sin destino, Barcelona, El Acantilado, [1975].

—, 2004. Diario de la galera, Madrid, El Acantilado, [1992].

—, 2004. Liquidación, México, Alfaguara, [2003].

Kertész, Imre y Hermann Terstch, 2001. "Existen medios para dominar al hombre", El País, 11 de marzo.

Min Tran Huy, 2005. "De l'enfer au néant", Le magazine littéraire, 438, enero.

SEMPrún, Jorge, 2002. La escritura o la vida, Barcelona, Tusquets, [1995].

Wilkinson, T., 2002. "Kaddish for a Stillborn Child?", The Hungarian Quarterly, XLIII:168, invierno. 